http://www.sciencedirect.com/science/article/pii/S0305440398903909

DOI: 10.1016/j.jas.2004.06.006

(http://dx.doi.org/10.1016/j.jas.2004.06.006)

\title{
IMPLICATIONS OF BURIAL ALTERATIONS ON LUMINESCENCE DATING OF ARCHAEOLOGICAL CERAMICS
}

N. Zacharias ${ }^{* 1}$, J. Buxeda i Garrigós ${ }^{2}$, H. Mommsen ${ }^{1}$, A. Schwedt ${ }^{1}$, V. Kilikoglou ${ }^{3}$ Journal of Archaeological Science, 32, 49-57 (2005)

*Corresponding author. Tel. +30 2106503316; Fax +30 2106519430

E-mail address: zacharias@ims.demokritos.gr (N.V. Zacharias) 


\title{
Implications of Burial Alterations on Luminescence Dating of Archaeological Ceramics
}

\author{
N. Zacharias ${ }^{* 2}$, J. Buxeda i Garrigós ${ }^{2}$, H. Mommsen ${ }^{1}$, A. Schwedt ${ }^{1}$, V. Kilikoglou ${ }^{3}$
}

1 Gruppe Archäometrie, Institut für Strahlen- und Kernphysik der Universität Bonn, Nussallee 14-16, D 53115 Bonn (Germany)

2 ERAUB, Dept. de Prehistòria, Història Antiga i Arqueologia, Universitat de Barcelona, C/ de Baldiri i Reixac, s/n, E-08028 Barcelona (Catalonia, Spain)

3 Laboratory of Archaeometry, Institute of Materials Science, NCSR Demokritos 15310 Aghia Paraskevi, Attiki (Greece)

\begin{abstract}
Recent mineralogical studies on archaeological pottery samples report significant variations in alkali metal concentrations due to environmental alterations during burial. Here we examine the effects of potassium $(\mathrm{K})$ leaching on luminescence dating. The effect on the estimation of the dose rate is studied by considering four models of leaching (exponential, linear, early and late) and their impact on fineand coarse-grain dating are calculated. The modeling approaches are applied to two cases of pottery in which evidence for alteration was found. Additionally, TL dating performed on pottery of one of the studied cases, indicates the importance of leaching effects on absolute dating measurements.
\end{abstract}

\section{KEYWORDS}

Luminescence dating, potassium leaching, Bronze Age pottery, over-fired pottery, calcareous pottery

\section{Introduction}

Both luminescence techniques, namely Thermoluminescence (TL) and Optically Stimulated Luminescence (OSL) are well established absolute dating techniques, the accuracy of which has been tested in several cases, either by archaeological criteria (Martini and Sibila, 2001) or by comparison

"Corresponding author. Tel. +30 2106503316; Fax +30 2106519430

E-mail address: zacharias@ims.demokritos.gr (N.V. Zacharias) 
studies using other indepented dating methods (Murray and Roberts, 1997; Rousseau et al., 2002). However the attainable accuracy on dose rate and consequently age determination remains an issue on which considerable amount of research is on the way (Galloway, 2001). Successful dose rate determination requires the precise estimation of many factors and knowledge of possible effects, such as sample inhomogeneity and radioactive secular disequilibrium. Moreover, the dose rate value of archaeological ceramics can be also affected by changes in $\mathrm{U}$, Th and $\mathrm{K}$ concentration undergone by pottery since its fabrication.

In that respect, for $\mathrm{U}$ and $\mathrm{K}$ there exist in the archaeometric literature several cases in which such processes have been proposed, to explain the enrichment of $U$ because of the proximity to an ore deposit (Asaro et al. 1975), and the enrichment of K either by being buried in wood ashes (Dufournier, 1979) or by the use of modern fertilizers (Readhead et al. 1988). However, the small changes these processes induce and/or the exceptional environmental conditions they need generally enable the usual application of TL or OSL dating in normal circumstances. A more widespread phenomenon affecting TL/OSL dating has been described by Hedges and McLellan (1976) and is linked to the cation exchange capacity (c.e.c.) of clays in pottery. These authors have demonstrated that, although it is clear that c.e.c. decreases due to clay decomposition as firing temperature increases, clay minerals in pottery keep an important c.e.c. even at firing temperatures up to $1000^{\circ} \mathrm{C}$. The extent at which this process can affect several trace elements (like $\mathrm{U}$ ) is generally fixed up to a maximum of around $10 \%$ of the original value, provided the concurrence of some special burial conditions, but such variations are much more difficult to take place for major and minor elements like $\mathrm{K}$. Therefore, due to the relatively small changes induced by the c.e.c. of clays is also possible that this process could not seriously affect luminescence dating, even for low fired pottery.

Furthermore, a completely different process has been identified as responsible for inducing severe changes in several alkali metals, mainly enrichment of sodium and, of interest here, leaching of potassium. This was first identified by Picon (1976) who demonstrated that this effect was predominant in high-fired or over-fired $\left(>1050^{\circ} \mathrm{C}\right)$ pottery of calcareous nature (i.e. $\left.\mathrm{CaO}>5-6 \%\right)$. In 
this study, the alteration of the extensive glassy phase, which is formed at these temperatures and can be rich in potassium, together with the crystallization of zeolites, was proposed as an explanation. During the 1980s several studies detected the same alteration process, and in the mid 1990s the crystallization of analcime, a sodic zeolite, most probably favored by the existence of free silica material in the altered glassy phase, was effectively determined (Buxeda, 1999 and references therein). Since then, the number of studies where this process has been observed has significantly increased (see especially Buxeda et al. 2001; Buxeda et al. 2002 with references therein), and the relationship with the calcareous nature of clay paste and the high-fired/over-fired state has been fully established.

Even if the implications of this process in provenance and technology have been already studied (Buxeda, 1999; Mommsen, 2001), the two latter factors, the severe potassium leaching and the widespread occurrence, may have also serious implications on luminescence dating of ancient pottery, introducing an additional source of inaccuracy. The $\mathrm{K}$ concentrations measured for luminescence dating may be lower from the original values, and age can then be overestimated. Considering two different case studies of Aegean Bronze Age pottery the effect of this leaching on absolute dating is being approached in this paper. For each case study, alterations have been detected after applying a combination of mineralogical and chemical analyses to pottery having the same provenance, and therefore with similar chemical compositions. The altered ceramics were identified by differences in concentration in alkali metals, compared to other members of the group, together with the identification of analcime by X-ray diffraction analysis (XRD). The effect of the observed alterations on the dose rate was then studied for four different models of leaching. Finally, fine grain TL dating results on three ceramic fragments belonging to the first case study are presented. One of these ceramics did not show alterations while the rest had undergone severe $\mathrm{K}$ leaching.

\section{Two cases of archaeological Bronze Age pottery}

Here we use two case studies for which alterations have been reported to exemplify the effect on the estimation of dose rate and the error in dating according to distinct 'leaching rates'. The first case 
deals with pottery recovered at the kiln site where it was fired, while the second case examines pottery with a common origin, but recovered from various archaeological sites, to which it was probably imported.

\subsection{The Kommos pottery}

Kommos, located in South-Central Crete, is considered archaeologically as an important Minoan site, which was the harbor town of the palatial center of Phaistos. Within the Stoa of one of the buildings a ceramic kiln, still containing pottery from its last firing, was excavated (Shaw et al., 2001). A large amount of pottery, of about 26,000 fragments, was found in and around the kiln, which represents wastes from its operation. Among the pottery, which is highly repetitive in fabric and form, there were more than 300 wasters distributed throughout the deposit along with many over-fired and deformed vessels. This constitutes archaeological evidence that the finds were products of the same workshop, which operated during the Late Minoan IA period.

A full archaeometric characterization of 57 samples coming from the kiln structure and the kiln dump has been performed in order to confirm the archeological / stylistic hypothesis, and the results have been published in detail (Shaw et al. 2001; Buxeda et al. 2001). The samples were characterized by a combination of techniques, which provide information on the chemical composition (neutron activation analysis -NAA, X-ray fluorescence analysis -XRF), mineralogy (X-ray diffraction -XRD,

petrographic examination -PE), and microstructure (scanning electron microscopy -SEM) of the ceramic body. Petrographic and chemical analysis revealed, as it is normal for a kiln site, that the raw materials used in the production of all the ceramics came from the same source (Shaw et al. 2001, Buxeda et al. 2001). In the same study it was however, shown, that certain samples exhibited remarkable deviations form the average values in alkali metals concentrations. (Table 1). More specifically, values of $\mathrm{K}$ and $\mathrm{Rb}$, were significantly lower in high-fired and over-fired (over 1000$1050^{\circ} \mathrm{C}$ ) samples (Table 1, Group B), while Na values were higher, than in the case of low-fired and medium-fired pottery (Table 1, Group A). This phenomenon was proved to be the result of leaching of 
$\mathrm{K}$ and $\mathrm{Rb}$ from the glassy phase with subsequent enrichment of $\mathrm{Na}$ due to the crystallization of analcime.

In order to confirm the potassium leaching from the glassy phase, one fragment from KOM26 (Table 1, Group A) was fired at $1050^{\circ} \mathrm{C}$ in oxidizing atmosphere for $1 \mathrm{~h}$, using a rate of $100^{\circ} \mathrm{C} \mathrm{h}^{-1}$, to ensure formation of an extensive network of glass in its microcrostructure. A polished section of this was then examined under an SEM-EDAX and the potassium content in the glassy phase was found to be $10 \%$ higher than the average value of Group A. The same examination was then performed on the overfired individuals KOM27 and KOM37 (Table 1, Group B). It was found that the K content in the glassy phase was at the $50 \%$ level of the global value, indicating that this is the source of the leaching that took place during burial.

\subsection{The MB - MBKR pottery groups}

In the second case study pottery belonging to the main reference group of Mycenaean decorated production was used. This group (MB) contains pottery coming either from Mycenae itself or from other sites, which imported pottery from Mycenae and has been formed over the years after systematic analysis, by NAA, of hundreds of samples (Mommsen et. al., 1988; Mommsen and Maran, 20002001; Mommsen, 2001). In addition, a smaller group called MBKR, which contains ceramics of the same style and fabric as that of MB, has been identified (Mommsen et al. 1996). Its composition is similar to that of the MB group, but with significant differences in some alkali metal concentrations, although from the stylistic point of view both groups should be of the same origin and therefore have the same chemical profile.

To further explore these chemical differences in alkali metal concentrations (Table 2), chemical analysis was followed by an XRD study (Buxeda et al. 2002) in order to examine the mineralogy. Nine samples belonging to the MB pattern and eleven to the MBKR pattern were analyzed. The results revealed that while samples belonging to the MB pattern were low-fired or medium-fired, the ones 
belonging to the MBKR pattern were always high-fired or over-fired (over $1000-1050^{\circ} \mathrm{C}$ ). Moreover, those samples belonging to the latter pattern contain analcime as it was the case in the previous example of Kommos pottery. In fact, both Mycenaean groups correspond to the same production, and therefore, to the same provenance, but samples in the MBKR group have undergone the alteration process, which resulted to significant deviation in alkali concentrations.

\section{The $\mathrm{K}$ contribution in dose rate estimation}

Once it has been established that the present differences of $\mathrm{K}$ content are not the original ones, but induced by an alteration process during burial and not before or during firing, it becomes necessary to quantify the impact that such different concentrations may have in the dose rate estimation.

As it is known the age equation given for luminescence dating is $A G E=D_{\mathrm{e}} / \mathrm{DR}$, in which the equivalent or archaeological dose $\left(D_{e}\right)$ relates to the intensity of the luminescence signal measured today, converted to radiation dose units (Gy), while the total dose rate term (DR) provides the rate of the radiation dose $\left(\mathrm{Gy} \mathrm{ka}^{-1}\right)$. The latter can be expressed as follows:

$$
\mathrm{DR}=\mathrm{D}_{\alpha}+\mathrm{D}_{\beta}+\mathrm{D}_{\gamma}+\mathrm{D}_{\mathrm{cos}}
$$

Where $-\alpha$ and $-\beta$ correspond to the radiation emitted by the radioactive elements of $\mathrm{U}, \mathrm{Th},{ }^{40} \mathrm{~K}$ and, in very small amounts, by $\mathrm{Rb}$ dominant in the ceramic matrix (internal contributions), $-\gamma$ to radiation emitted from $\mathrm{U}$, Th and ${ }^{40} \mathrm{~K}$ of the surrounding soil (external contribution), and cosmic radiation $\left(\mathrm{D}_{\cos }\right)$.

The two main methodologies for luminescence dating are fine-grain (polymineral grain fraction 2-8 $\mu \mathrm{m})$ and coarse-grain (single mineral grain fractions of 90-250 $\mu \mathrm{m}$ ) techniques. In the equation below, a more detailed formula of the parameters calculated in the dose rate is given for these two techniques. For coarse-grain dating, the $\alpha$-dose is usually omitted by etching sufficiently the grain surface that has 
received $\alpha$-dose from the ceramic matrix and the $\beta$-dose is corrected for attenuation effects (Mejdahl, 1979).

$\mathrm{DR}=\left(\mathrm{aD}_{\alpha(\mathrm{U}, \mathrm{Th})} /(1+1.5 \mathrm{WF})\right)+\left(\mathrm{D}_{\beta(\mathrm{U}, \mathrm{Th}, \mathrm{K}, \mathrm{Rb})} /(1+1.25 \mathrm{WF})\right)+\left(\mathrm{D}_{\gamma(\mathrm{U}, \mathrm{Th}, \mathrm{K})} /\left(1+1.14 \mathrm{~W}_{1} \mathrm{~F}\right)\right)+\mathrm{D}_{\cos }(2)$

The correction factors of $\mathrm{W}$ and $\mathrm{F}$ in equation 2 refer to the porosity of the sample $\left(\mathrm{W}_{1}\right.$ to that of the soil) and to the fractional uptake of water averaged over the burial period and a-value is a correction for the effectiveness of the alpha particles. The cosmic and gamma dose contribution (equation 1) is usually referred as the environmental dose $\left(\mathrm{D}_{\text {env }}\right)$. For the calculation of $\mathrm{D}_{\alpha(\mathrm{U}, \mathrm{Th})}$ and $\mathrm{D}_{\beta(\mathrm{U}, \mathrm{Th}, \mathrm{K}, \mathrm{Rb})}$ measured in the ceramic body, the latest conversion factors introduced by Adamiec and Aitken (1998), are used.

To produce a quantitative estimation of $\mathrm{K}$ concentration in DR and the consequent age calculation, the mean concentration values of $\mathrm{U}$, Th and $\mathrm{K}$ for the two case studies (Table 1 and 2) were used. In the same calculations two extreme environmental dose rates from our data bank were taken. The $\mathrm{Rb}$ contribution was not included in the calculations because of its insignificant contribution to the DR value (less than $1 \%$ ). $\mathrm{K}$ makes a significant contribution even with the many assumptions about the environmental dose, a-value, $\mathrm{W}$ and $\mathrm{F}$ values (Table 3 ). The difference in the DR values for both initial and deviating mean $\mathrm{K}$ concentrations is also presented, as percentage (in parenthesis). For the latter we underline the large deviation of the calculated values in the range of ca. 15-35\%. These observations confirm the contribution of the effects of alteration to the correct estimation of luminescence ages and highlight the need for a procedure that can indicate alterations in the samples to be dated.

\section{Possible errors on DR estimation for KOMMOS and MB-MBKR altered pottery}

The previously calculated differences induced by $\mathrm{K}$ in dose rate calculation raise the important question that when and in which way does this difference, induced by burial alteration, appears. It is 
rather obvious that if they were produced in the first days of the burial period they would have had no consequences whatsoever for dating purposes, since the calculated dose rate would be the right one for the period of time involved. On the contrary, if we can imagine that all this $\mathrm{K}$ was leached just before the sherds were excavated, it is then clear that the calculated K-dose rate would have no relation with the internal contribution during the burial period.

These two extreme models will be approached here by the early model, in which it is assumed that the leaching effect occurred during the very early years of burial, and by the late model, in which it is assumed that this effect took place during the late years. Moreover, two other different models for K leaching (exponential and linear) are considered, in order to approximate intermediate possibilities. To study these four different models (Figure 1) we estimated average $\mathrm{K}$ concentration values and the resulting K-dose and DR values, for the archaeological periods of 3.6 and $3.2 \mathrm{ka}$ for the Kommos and MB-MBKR pottery, respectively.

In the exponential model, the $\mathrm{K}$ concentration $(\mathrm{C})$ at a given time $(\mathrm{t})\left(\mathrm{C}_{\mathrm{t}}\right)$ is related to the initial concentration $\left(\mathrm{C}_{0}\right)$ according to equation 3 . By inserting boundary values (e.g. $\mathrm{C}_{0}=3 \%$ and $\mathrm{C}_{\mathrm{T}}=1.3 \%$ for the present time T, referring to the MB-MBKR pottery), the value of constant $\lambda$ (in equation 4) is estimated.

$\mathrm{C}_{\mathrm{t}}=\mathrm{C}_{0} \mathrm{e}^{-\lambda \mathrm{t}}$

$\lambda=\frac{\ln \mathrm{C}_{0}-\ln \mathrm{C}_{\mathrm{t}}}{\mathrm{t}}$

In contrast, in the linear model (equation 5) and using the same boundary values for the $\mathrm{K}$ concentrations as above, the $\lambda$ value is estimated from equation 6

$\mathrm{C}_{\mathrm{t}}=\mathrm{C}_{0}-\lambda \mathrm{t}$ 
$\lambda=\frac{\mathrm{C}_{0}-C_{\mathrm{t}}}{\mathrm{t}}$

By using the resulting $\lambda$ values, the average concentration values $C_{\text {ave }}$ for a time period (e.g. $T=3.2 \mathrm{ka}$ for the MB-MBKR case study) are calculated from equation 7, for exponential and linear leaching alternatively.

Cave $=\frac{1}{\mathrm{t}} \int_{0}^{\mathrm{t}} \mathrm{C}_{\mathrm{t}} \mathrm{dt}$

The calculated deviations of the DR values (Table 4), for the proposed approaches of leaching were estimated by comparison with the results obtained from the early leaching model. This does not imply that early leaching is more possible, but only that in this model the calculated K-dose rate is equal to the dose measured today without the assumption of leaching while performing luminescence dating. Obviously, leaching during later stages of burial is the worst scenario for performing luminescence dating on altered ceramics since the $\mathrm{K}$-dose rate estimated today is calculated without considering any effect of leaching and therefore will result in highest age deviation.

In coarse-grain dating, internal K-dose makes a great contribution to the DR value (Table 3) -ca. 20\% more than in fine-grain dating-which leads the significant deviation of the values in Table 4. Although we assumed the same values for environmental dose, a-value, porosity and saturation effects for the calculation of the DR values, resulting values that differ greatly clearly indicate the significance of alteration and contamination effects, especially in cases where high precision dating is required.

\section{TL dating}

To present we have demonstrated the existence of an alteration process that can seriously affect the dose rate estimation. However, the potential source for luminescence dating really depends on the actual model of leaching process undergone by pottery during burial. By considering that only 
luminescence ages could assess the degree of implication of leaching effects to absolute dating, three ceramic fragments were selected from the Kommos pottery in order to perform TL dating measurements. Kommos case study was chosen for this exercise since all vessels manufactured in this kiln should be considered as contemporary and also because of the same environmental radiation dose these sherds were most probably suffered. Therefore, resulting deviation in dating between altered and unaltered sherds must be due to the error induced by the dose rate estimated.

To perform this experiment, three samples were selected: on the one hand KOM26 from the unaltered sherds (Table 1, Group A), and on the other hand KOM27 and KOM37 from the altered ones (Table 1, Group B). These samples were the only ones that were available having an adequate size for the performance of complete TL age estimation. The rather limited size of the fragments and their microscopically examination which showed very low abundance of inclusions restricted the application of only fine grain TL dating protocols.

For the sample preparation and $\mathrm{D}_{\mathrm{e}}$ estimation the foil technique procedure was followed (Michael et al., 1997). Grains in the range of $2-8 \mu \mathrm{m}$ were obtained by gently crushing the fragments using a vice and applying the settlement technique. Totally 25-30 aliquots were prepared from every ceramic fragment. The TL glow curves were recorded with conventional Littlemore, 711 TL equipment and an EMI 9635A photomultiplier with a Corning 7-59 blue filter. The heating rate was $10{ }^{\circ} \mathrm{C} . \mathrm{s}^{-1}$ and the irradiations were administered with a ${ }^{90} \mathrm{Sr} \beta$-source $\left(2.0 \pm 0.1 \mathrm{~Gy} \cdot \mathrm{min}^{-1}\right)$.

Using the foil technique, a second glow normalization with the same laboratory dose is made after the first glow measurement of every aliquot. The $D_{e}$ values (Figure 2) are resulted from growth curves where each point in the growth provides the ratio of the TL intensity of the first to the second glow for the same point in the temperature range. Usually 15 aliquots are used for estimation of the normalized natural TL intensities $\left(r_{o}\right)$ and for the natural TL + additive dose points $\left(r_{D}\right)$ to form a growth curve. 
The DR calculations were based on the assumption that secular disequilibrium in the $\mathrm{U}$ and $\mathrm{Th}$ series is not a possibility since the clay deposits in the neighborhood area are ascribed to the Miocene geological period (10-15 Ma BP).

In Table 5 the results on the estimation of an average K concentration value for samples KOM27 and KOM37 and also calculated dose rate values, based on equation 2, are showed. First, by considering that sample KOM26 did not exhibit leaching effects and that all samples were ascribed at a well established archaeological age, the determination of the environmental dose rate $\mathrm{D}_{\text {env }}$ is resulted (Table 5.a). This value was then subsequently used for the estimation of average $K$ and new dose rate values (DR') for samples KOM27 and KOM37 (Table 5.b). It can be easily seen that the calculated average and measured $\mathrm{K}$ values deviate in the range of $28-38 \%$ and their resulting different DR values points to an additional TL age error of $9 \%$ and $11 \%$ for sample KOM27 and KOM37, respectively. These results give clear evidence that in the present case early model should not be considered and, therefore, any TL dating on altered sherd from Kommos would result in an overestimation of age.

\section{Conclusions}

Calcareous archaeological pottery can be subjected to chemical and mineralogical alterations in cases of high-firing or over-firing resulting to a significant $\mathrm{K}$ leaching. For the cases studied here, leaching yielded ca. $50 \%$ of the original $\mathrm{K}$ value, while the concentrations of the radioactive elements $\mathrm{U}$ and $\mathrm{Th}$ remained stable, usually within experimental errors. Because of these observations, and the widespread occurrence of this alteration process, the additional use of mineralogical analysis is strongly recommended $\mathrm{A}$ when luminescence dating is attempted on sherds that show signs of overfiring.

In general, when the effects of leaching occur during very early burial then luminescence dating is not affected. On the contrary, if leaching takes place during later periods of burial, shifted luminescence dating results are expected. 
Even if more work is needed in order to understand the exact model followed for potassium leaching during this alteration process, the Kommos case study has enable the application of fine-grain TL dating. In this experiment it has been demonstrated that for Kommos the early model cannot be sustained, and in such circumstances any TL dating would have resulted to an age overestimation of ca. $10 \%$.

\section{Acknowledgements}

The authors thank Drs. G. Adamiec and S. Thanos for their helpful remarks. The work presented here forms part of the GEOPRO Research Network funded by DGXII of the European Commission, under the Training and Mobility of Researchers Network Programme (Contract number ERBFMRX-CT980165). We are most grateful to TMR in the European Commission for funding our collaborative work. SEM-EDX analyses were undertaken at the Serveis Cientificotècnics de la Universitat de Barcelona. TL dating was undertaken at the Laboratory of Archaeometry, NCSR Demokritos. 


\section{References}

Adamiec, G. \& Aitken, M.J. (1998). Dose-rate conversion factors: update. Ancient TL, 16, 37-50.

Aitken, M.J. (1985). Thermoluminescence dating. London: Academic Press.

Asaro, F. Michel, H. Widemann, F. \& Fillières-Kunetz, D. (1975). Étude analytique de la provenance d'un vase signé C. CIN() SENOVIRI trouvé à Salelles, Le Bosc (Hérault). Gallia, 33, 225-228.

Buxeda i Garrigós, J. (1999). Alteration and Contamination of Archaeological Ceramics: The Perturbation Problem. Journal of Archaeological Science, 26, 295-313.

Buxeda i Garrigós, J. Kilikoglou, V. \& Day, P.M. (2001). Chemical and mineralogical alteration of ceramics from a Late Bronze Age kiln at Kommos, Crete: the effect on the formation of a reference group. Archaeometry, 43, 349-371.

Buxeda i Garrigós, J. Mommsen, H. \& Tsolakidou, A. (2002). Alterations of Na, K and Rb concentrations in Mycenaean pottery and a proposed explanation using X-ray diffraction. Archaeometry, 44, 187-198.

Dufournier, D. (1979). Deux exemples de contamination des céramiques anciennes par leur milieu de conservation. Figlina, 4, 69-83.

Galloway, R.B. (2001). Luminescence dating: Limitations to accuracy attainable. Journal of Radioanalytical and Nuclear Chemistry, 247, No.3, 679-683. 
Hedges, R.E.M. \& McLellan, M. (1976). On the cation exchange capacity of fired clays and its effect on the chemical and radiometric analysis of pottery. Archaeometry, 18, 203-207.

Martini, M. \& Sibila, E. (2001). Radiation in archaeometry: archaeological dating. Radiation Physics and Chemistry, 61, 241-246.

Mejdahl, V. (1979). Thermoluminescence dating: Beta-dose attenuation in quartz grains. Archaeometry, 21, 61-73.

Michael, C.T. Zacharias, N. Dimotikali, D. \& Maniatis, Y. (1997). A new technique (foil technique) for measuring the natural dose in TL dating and its application in the dating of a mortar containing ceramic grains. Ancient TL, 15, 36-42.

Mommsen, H. (2001). Provenance determination of pottery by trace element analysis: Problems, solutions and applications. Journal of Radioanalytical and Nuclear Chemistry, 247, No.3, 657-662.

Mommsen, H. \& Maran, J. (2000-2001). Production places of some Mycenaean Pictorial vessels - the contribution of chemical pottery analysis. Opuscula Atheniensia, 25-26, 95-106.

Mommsen, H. Beier, T. Hein, A. Podzuweit, Ch. Pusch, E.B. \& Eggebrecht, A. (1996). Neutron Activation Analysis of Mycenaean sherds from the town of Ramses II near Qantir and Greek-Egyptian trade relations. Proceedings of Archaeometry '94 (eds. S. Demirci, A.M. Oezer and G.D. Symmers), 169-178, Tuebitak.

Mommsen, H. Lewandowski, E. Weber, J. \& Podzuweit, Ch. (1988). Neutron Activation Analysis of Mycenaean Pottery from the Argolid: The search for Reference Groups. Proceedings of the $26^{\text {th }}$ International Archaeometry Symposium (eds. R.M. Farquhar, R.G.V. Hancock and L.A. Pavlish), 165-171, The Archaeometry Laboratroy, University of Toronto, Toronto. 
Murray, A.S. \& Roberts, R.G. (1997). Determining the burial time of single grains of quartz using optically stimulated luminescence. Earth and Planetray Science Letters, 152, 163-180.

Picon, M. (1976). Remarques preliminaries sur deux types d'altération de la composition chimique des céramiques au cours du temps. Figlina, 1, 159-166.

Readhead, M. Dunnell, R.C. \& Feathers, J.K. (1988). Recent addition of potassium: A potential source of error in calculating TL ages. Ancient TL, 6, 1-4.

Rousseau, .D. Antoine, P. Hatte, C. Lang, A. Zöller, L. Fortugne, M. Ben Othman, D. Luck, J.M. Moine, O. Labonne, I. Bentaleb, I. \& Jolly, D. (2002). Abrupt millennial climatic changes from Nussloch (Germany) Upper Weichselian eolian records during the Last Glaciation. Quaternary Science Reviews, 21, 1577-1582.

Shaw, J. Van de Moortel, A. Day, P.M. \& Kilikoglou, V. (2001). A LM IA Ceramic Kiln in SouthCentral Crete. Function and Pottery Production. Hesperia Supplement 30, Princeton. 


\begin{tabular}{l|ccccc} 
GROUP A & $\mathbf{N a}(\boldsymbol{\%})$ & $\mathbf{K}(\boldsymbol{\%})$ & $\mathbf{R b}(\mathbf{p p m})$ & $\mathbf{T h}(\mathbf{p p m})$ & $\mathbf{U}(\mathbf{p p m})$ \\
\hline Kom15 & $0.71(0.004)$ & $2.03(0.05)$ & $78.3(2.50)$ & $9.40(0.15)$ & $1.93(0.06)$ \\
Kom16 & $0.55(0.005)$ & $1.99(0.04)$ & $137.3(3.85)$ & $9.49(0.09)$ & $2.65(0.08)$ \\
Kom25 & $0.74(0.004)$ & $1.91(0.04)$ & $86.7(2.88)$ & $9.80(0.11)$ & $2.69(0.07)$ \\
Kom26 & $0.60(0.004)$ & $2.37(0.07)$ & $141.9(3.40)$ & $9.29(0.10)$ & $1.86(0.06)$ \\
Kom31 & $0.74(0.004)$ & $2.06(0.04)$ & $133.4(3.23)$ & $9.95(0.10)$ & $1.68(0.06)$ \\
Kom35 & $0.37(0.003)$ & $2.23(0.07)$ & $99.2(2.44)$ & $9.98(0.09)$ & $1.77(0.08)$ \\
Kom40 & $0.73(0.006)$ & $1.65(0.04)$ & $84.9(2.34)$ & $10.30(0.15)$ & $3.27(0.09)$ \\
Kom57 & $0.45(0.006)$ & $1.78(0.04)$ & $102.2(2.96)$ & $9.93(0.09)$ & $2.70(0.11)$ \\
\hline mean (M) & 0.61 & 2.0 & 107.8 & 9.77 & 2.32 \\
\hline std. deviation & 0.14 & 0.23 & 25.8 & 0.34 & 0.58 \\
\hline in \% & 23. & 11.5 & 23.9 & 3.48 & 25
\end{tabular}

\begin{tabular}{l|ccccc} 
GROUP B & Na $(\%)$ & $\mathbf{K}(\boldsymbol{\%})$ & $\mathbf{R b}(\mathbf{p p m})$ & $\mathbf{T h}(\mathbf{p p m})$ & $\mathbf{U}(\mathbf{p p m})$ \\
\hline Kom27 & $0.86(0.05)$ & $0.99(0.04)$ & $62.29(1.88)$ & $7.83(0.09)$ & $3.12(0.12)$ \\
Kom37 & $1.16(0.05)$ & $0.80(0.03)$ & $39.78(1.07)$ & $8.80(0.20)$ & $3.18(0.11)$ \\
Kom46 & $0.97(0.04)$ & $1.25(0.04)$ & $85.26(2.03)$ & $8.15(0.13)$ & $1.58(0.09)$ \\
Kom49 & $1.11(0.04)$ & $0.86(0.03)$ & $52.45(2.01)$ & $8.84(0.09)$ & $1.86(0.08)$ \\
\hline mean (M) & 1.03 & 0.98 & 59.94 & 8.4 & 2.44 \\
\hline std. deviation & 0.18 & 0.17 & 16.7 & 0.43 & 0.72 \\
\hline in \% & 17. & 17.3 & 27.9 & 5.1 & 29.6
\end{tabular}

Table 1. NAA and XRF results of the two groups originated from the deviations in alkali metal values $(\mathrm{Na}, \mathrm{K}, \mathrm{Rb})$ at Kommos, Crete: elemental concentrations, experimental errors (in paranthesis), mean (M) and standard deviation also as percentage of M. Th and U are presented for both groups since they are involved in the dose rate estimation. 


\begin{tabular}{l|ccccc} 
MB group & $\mathbf{N a}(\boldsymbol{\%})$ & $\mathbf{K}(\boldsymbol{\%})$ & $\mathbf{R b}(\mathbf{p p m})$ & $\mathbf{T h}(\mathbf{p p m})$ & $\mathbf{U}(\mathbf{p p m})$ \\
\hline Tiry 28 & $0.39(0.004)$ & $3.24(0.04)$ & $158 .(3.16)$ & $10.7(0.08)$ & $2.17(0.07)$ \\
Tiry 29 & $0.59(0.005)$ & $2.90(0.04)$ & $141 .(2.97)$ & $10.6(0.07)$ & $2.25(0.07)$ \\
Tiry 30 & $0.31(0.004)$ & $3.47(0.04)$ & $146 .(3.03)$ & $10.5(0.07)$ & $2.18(0.07)$ \\
Tiry 39 & $0.52(0.005)$ & $3.03(0.05)$ & $159 .(3.20)$ & $10.8(0.08)$ & $2.30(0.08)$ \\
Kirr 86 & $0.87(0.004)$ & $2.57(0.02)$ & $140 .(2.05)$ & $10.3(0.05)$ & $5.37(0.02)$ \\
Kirr 87 & $0.81(0.003)$ & $2.72(0.02)$ & $155 .(2.15)$ & $11.0(0.06)$ & $2.68(0.10)$ \\
Kirr 88 & $0.70(0.003)$ & $2.88(0.02)$ & $163 .(2.20)$ & $11.6(0.06)$ & $2.70(0.10)$ \\
Kirr 89 & $0.57(0.003)$ & $2.92(0.02)$ & $173 .(2.31)$ & $11.9(0.06)$ & $2.90(0.10)$ \\
Kirr 90 & $0.85(0.004)$ & $2.89(0.02)$ & $152 .(2.14)$ & $11.2(0.06)$ & $3.47(0.11)$ \\
\hline mean (M) & 0.62 & 3.0 & 154. & 11. & $2.9(2.59)$ \\
\hline std. deviation & 0.20 & 0.27 & 11. & 0.53 & $1.0(0.45)$ \\
\hline in \% & 32. & 9. & 6.9 & 4.9 & $35(16.8)$
\end{tabular}

\begin{tabular}{l|ccccc} 
MBKR group & $\mathbf{N a}(\boldsymbol{\%})$ & $\mathbf{K}(\boldsymbol{\%})$ & $\mathbf{R b}(\mathbf{p p m})$ & $\mathbf{T h}(\mathbf{p p m})$ & $\mathbf{U}(\mathbf{p p m})$ \\
\hline Berb 27 & $0.94(0.014)$ & $1.20(0.04)$ & $96.2(2.59)$ & $10.1(0.08)$ & $2.13(0.03)$ \\
Berb 49 & $1.19(0.003)$ & $1.61(0.01)$ & $144 .(2.58)$ & $12.1(0.07)$ & $2.44(0.02)$ \\
Berb 51 & $1.16(0.003)$ & $1.20(0.01)$ & $118 .(2.32)$ & $10.7(0.07)$ & $2.12(0.02)$ \\
Kats 73 & $1.30(0.006)$ & $1.22(0.02)$ & $73.7(1.75)$ & $11.7(0.06)$ & $2.51(0.05)$ \\
Kirr 83 & $1.30(0.003)$ & $1.43(0.02)$ & $86.9(2.35)$ & $11.0(0.06)$ & $2.53(0.05)$ \\
Kirr 84 & $1.15(0.004)$ & $1.52(0.02)$ & $89.1(2.30)$ & $11.4(0.06)$ & $2.58(0.05)$ \\
Kirr 85 & $1.35(0.003)$ & $1.54(0.02)$ & $92.7(2.81)$ & $10.9(0.07)$ & $3.46(0.04)$ \\
Qant 15 & $1.47(0.008)$ & $0.87(0.03)$ & $49.3(1.63)$ & $11.0(0.06)$ & $2.26(0.06)$ \\
Qant 23 & $1.42(0.010)$ & $1.14(0.03)$ & $54.3(1.70)$ & $11.2(0.06)$ & $2.40(0.06)$ \\
Qant 28 & $1.54(0.010)$ & $1.26(0.04)$ & $71.9(1.84)$ & $11.5(0.06)$ & $2.40(0.06)$ \\
Qant 50 & $1.49(0.010)$ & $1.09(0.04)$ & $42.1(1.70)$ & $10.9(0.06)$ & $2.50(0.07)$ \\
\hline mean (M) & 1.3 & 1.3 & 84. & 11.1 & 2.46 \\
\hline std. deviation & 0.17 & 0.22 & 29. & 0.51 & 0.35 \\
\hline in \% & 13. & 17. & 34. & 2.6 & 16
\end{tabular}

Table 2. NAA results of the MB and MBKR pottery groups identified at the sites of Berbati, Tiryns, Katsingri in the Argolid (Greece), Kirra near Delphi (Greece) and Qantir (Egypt): elemental concentrations, experimental errors (in parenthesis), mean (M) and standard deviation, also as percentage of M. In parenthesis mean, standard deviation and its percentage of $\mathrm{M}$ for $\mathrm{U}$, in MB group, excluding the abnormal Kirr86 concentration. Th and $\mathrm{U}$ are presented for both groups since they are involved in the dose rate estimation. 


\begin{tabular}{|c|c|c|c|c|c|}
\hline \multirow{3}{*}{$\begin{array}{l}\text { KOMMOS } \\
\text { pottery }\end{array}$} & Technique & $\begin{array}{c}\begin{array}{c}\text { K-dose rate } \\
\left(\mathbf{G y ~ k a}^{-1}\right)\end{array} \\
(2 \% \mathrm{~K}-0.98 \% \mathrm{~K})\end{array}$ & $\begin{array}{c}D_{\text {env }} \\
\left(\text { Gy ka }^{-1}\right)\end{array}$ & $\begin{array}{c}\text { DR } \\
\left(\mathbf{G y ~ k a}^{-1}\right) \\
(2 \% \mathrm{~K}-0.98 \% \mathrm{~K})\end{array}$ & $\begin{array}{c}\text { K contribution } \\
(\%) \\
(2 \% \mathrm{~K}-0.98 \% \mathrm{~K})\end{array}$ \\
\hline & Fine Grain & $1.35-0.66$ & $\begin{array}{l}0.5 \\
1.0\end{array}$ & $\begin{array}{l}3.76-3.07(\mathbf{1 8 \%}) \\
4.26-3.57(\mathbf{1 6 \%})\end{array}$ & $\begin{array}{l}36-22 \\
32-19\end{array}$ \\
\hline & Coarse Grain & $1.22-0.59$ & $\begin{array}{l}0.5 \\
1.0\end{array}$ & $\begin{array}{l}2.18-1.55(\mathbf{2 9 \%}) \\
2.68-2.05(\mathbf{2 4 \%})\end{array}$ & $\begin{array}{l}56-38 \\
46-29\end{array}$ \\
\hline
\end{tabular}

\begin{tabular}{|c|c|c|c|c|c|}
\hline \multirow{3}{*}{$\begin{array}{l}\text { MB-MBKR } \\
\text { pottery }\end{array}$} & Technique & $\begin{array}{c}\begin{array}{c}\text { K-dose rate } \\
(\mathbf{G y ~ k a - 1})\end{array} \\
(3 \% \mathrm{~K}-1.3 \% \mathrm{~K})\end{array}$ & $\begin{array}{c}\mathbf{D}_{\text {env }} \\
\left(\text { Gy ka }^{-1}\right)\end{array}$ & $\begin{array}{c}\text { DR } \\
(\mathbf{G y ~ k a - 1}) \\
(3 \% \mathrm{~K}-1.3 \% \mathrm{~K})\end{array}$ & $\begin{array}{c}\text { K contribution } \\
(\%) \\
(3 \% \mathrm{~K}-1.3 \% \mathrm{~K})\end{array}$ \\
\hline & Fine Grain & $2.03-0.88$ & $\begin{array}{l}0.5 \\
1.0\end{array}$ & $\begin{array}{l}4.68-3.53(\mathbf{2 5 \%}) \\
5.18-4.03(\mathbf{2 2 \%})\end{array}$ & $\begin{array}{l}43-25 \\
39-22\end{array}$ \\
\hline & Coarse Grain & $1.83-0.79$ & $\begin{array}{l}0.5 \\
1.0\end{array}$ & $\begin{array}{l}2.84-1.81(\mathbf{3 6 \%}) \\
3.34-2.31(\mathbf{3 1 \%})\end{array}$ & $\begin{array}{l}64-44 \\
55-34\end{array}$ \\
\hline
\end{tabular}

Table 3. K contribution of the ceramic body as a percentage of the total dose rate (DR). The concentrations used were U $2.36 \mathrm{ppm}$ and Th $9.31 \mathrm{ppm}$ for the Kommos pottery (Table 1), and U $2.5 \mathrm{ppm}$ and Th $11 \mathrm{ppm}$ for the MB and MBKR pottery (Table 2). K-dose rates, DR values and K contribution to the DR were estimated for the unaltered and altered mean K concentrations. Also the deviation from the unaltered DR values is given in parentheses. The a-value was assumed as $0.15, \mathrm{~W}$ and $\mathrm{F}$ values were taken as 0.25 and 0.5 respectively. The coarse grain approach was based on quartz grains that ranged between $90-120 \mu \mathrm{m}$. The two extreme values of $0.5 \mathrm{~Gy} \mathrm{ka}^{-1}$ and $1.0 \mathrm{~Gy} \mathrm{ka}^{-1}$ for the environmental dose were recorded with a portable NaI scintillator at various archaeological sites in Greece over the last 15 years. Values in percentage were rounded. 


\begin{tabular}{|l|l|c|c|c|c|}
\hline \multicolumn{2}{|l|}{ KOMMOS } & Early model & Exponential & Linear & Late model \\
\hline \multicolumn{2}{|l|}{ K average } & $0.98 \%$ & $1.43 \%$ & $1.49 \%$ & $2 . \%$ \\
\hline \multirow{2}{*}{ K-dose rate } & F.G. & $0.66 \mathrm{~Gy} \mathrm{ka}^{-1}$ & $0.97 \mathrm{~Gy} \mathrm{ka}^{-1}$ & $1.01 \mathrm{~Gy} \mathrm{ka}^{-1}$ & $1.35 \mathrm{~Gy} \mathrm{ka}^{-1}$ \\
\cline { 2 - 6 } & C.G. & $0.59 \mathrm{~Gy} \mathrm{ka}^{-1}$ & $0.87 \mathrm{~Gy} \mathrm{ka}^{-1}$ & $0.91 \mathrm{~Gy} \mathrm{ka}^{-1}$ & $1.22 \mathrm{~Gy} \mathrm{ka}^{-1}$ \\
\hline \multirow{2}{*}{ DR } & F.G. & $3.27 \mathrm{~Gy} \mathrm{ka}^{-1}$ & $3.58 \mathrm{~Gy} \mathrm{ka}^{-1}$ & $3.62 \mathrm{~Gy} \mathrm{ka}^{-1}$ & $3.96 \mathrm{~Gy} \mathrm{ka}^{-1}$ \\
\cline { 2 - 6 } & C.G. & $1.75 \mathrm{~Gy} \mathrm{ka}^{-1}$ & $2.03 \mathrm{~Gy} \mathrm{ka}^{-1}$ & $2.07 \mathrm{~Gy} \mathrm{ka}^{-1}$ & $2.38 \mathrm{~Gy} \mathrm{ka}^{-1}$ \\
\hline \multirow{2}{*}{ Deviation } & F.G. & - & $9 \%$ & $11 \%$ & $21 \%$ \\
\cline { 2 - 6 } & C.G. & - & $16 \%$ & $18 \%$ & $36 \%$ \\
\hline
\end{tabular}

\begin{tabular}{|l|l|c|c|c|c|}
\hline \multicolumn{2}{|l|}{ MB-MBKR } & Early model & Exponential & Linear & Late model \\
\hline \multicolumn{2}{|l}{ K average } & $1.30 \%$ & $2.03 \%$ & $2.15 \%$ & $3 . \%$ \\
\hline \multirow{2}{*}{ K-dose rate } & F.G. & $0.88 \mathrm{~Gy} \mathrm{ka}^{-1}$ & $1.37 \mathrm{~Gy} \mathrm{ka}^{-1}$ & $1.45 \mathrm{~Gy} \mathrm{ka}^{-1}$ & $2.03 \mathrm{~Gy} \mathrm{ka}^{-1}$ \\
\cline { 2 - 6 } & C.G. & $0.80 \mathrm{~Gy} \mathrm{ka}^{-1}$ & $1.23 \mathrm{~Gy} \mathrm{ka}^{-1}$ & $1.31 \mathrm{~Gy} \mathrm{ka}^{-1}$ & $1.83 \mathrm{~Gy} \mathrm{ka}^{-1}$ \\
\hline \multirow{2}{*}{ DR } & F.G. & $3.73 \mathrm{~Gy} \mathrm{ka}^{-1}$ & $4.23 \mathrm{~Gy} \mathrm{ka}^{-1}$ & $4.31 \mathrm{~Gy} \mathrm{ka}^{-1}$ & $4.88 \mathrm{~Gy} \mathrm{ka}^{-1}$ \\
\cline { 2 - 6 } & C.G. & $2.01 \mathrm{~Gy} \mathrm{ka}^{-1}$ & $2.45 \mathrm{~Gy} \mathrm{ka}^{-1}$ & $2.52 \mathrm{~Gy} \mathrm{ka}^{-1}$ & $3.04 \mathrm{~Gy} \mathrm{ka}^{-1}$ \\
\hline \multirow{2}{*}{ Deviation } & F.G. & - & $13 \%$ & $16 \%$ & $31 \%$ \\
\cline { 2 - 6 } & C.G. & - & $22 \%$ & $25 \%$ & $51 \%$ \\
\hline
\end{tabular}

Table 4. K concentrations and resulted deviations in DR values for the proposed models of leaching. The deviations in percentage were estimated by comparison with the early model DR value. The same values as in Table 3 were assumed for a-value and $\mathrm{W}, \mathrm{F}$ while for environmental dose a mean value of $0.7 \mathrm{~Gy} \mathrm{ka}^{-1}$ was used. Also, as in Table 3, the coarse grain approach was based on quartz grains (90$120 \mu \mathrm{m})$. For the $\mathrm{U}$ and $\mathrm{Th}$ concentrations, the mean values from Tables 1 and 2 were used. F.G., fine grain, C.G., coarse grain. Deviated values were rounded. 

Table 5a.

\begin{tabular}{|l|l|c|c|c|c|c|c|}
\hline Sample & AGE $(\mathbf{k a})$ & $\mathbf{E D}(\mathbf{G y})$ & $\mathbf{W}$ & $\mathbf{D}_{\boldsymbol{\alpha}}\left(\mathbf{G y ~ k a}^{\mathbf{- 1}}\right)$ & $\mathbf{D}_{\boldsymbol{\beta}(\mathbf{U}, \mathbf{T h}, \mathbf{K})}\left(\mathbf{G y ~ k a}^{-\mathbf{1}}\right)$ & $\left.\mathbf{D R}_{(\mathbf{G y ~ k a}} \mathbf{k}^{-\mathbf{1}}\right)$ & $\mathbf{D}_{\mathbf{e n v}}\left(\mathbf{G y ~ k a}^{\mathbf{- 1}}\right)$ \\
\hline KOM26 & $3.6 \pm 0.05$ & $13.2 \pm 0.88$ & $0.17 \pm 0.03$ & $0.97 \pm 0.12$ & $2.15 \pm 0.15$ & $3.67 \pm 0.25$ & $\mathbf{0 . 5 4} \pm \mathbf{0 . 0 6}$ \\
\hline
\end{tabular}

Table 5b.

\begin{tabular}{|c|c|c|c|c|c|c|c|c|c|c|}
\hline Sample & $\begin{array}{c}\text { AGE } \\
\text { (ka) }\end{array}$ & ED (Gy) & $\mathbf{W}$ & $\mathbf{D}_{\alpha}\left(\mathrm{Gy} \mathrm{ka}^{-1}\right)$ & $\mathbf{D}_{\beta(\mathrm{U}, \mathrm{Th})}\left(\mathbf{G y ~ k a}^{-1}\right)$ & $D_{\text {env }}\left(G_{y} k^{-1}\right)$ & DR $\left(G_{y ~ k a}{ }^{-1}\right)$ & $\mathbf{D}_{\beta(\mathbf{K})}\left(\mathbf{G y ~ k a}^{-1}\right)$ & $\begin{array}{c}\% \mathrm{~K} \\
\text { average }\end{array}$ & $\begin{array}{c}\mathrm{DR}^{\prime} \\
\left(\mathrm{Gy} \mathrm{ka}^{-1}\right) \\
\end{array}$ \\
\hline KOM27 & $3.6 \pm 0.05$ & $10.84 \pm 1.15$ & $0.20 \pm 0.04$ & $0.93 \pm 0.12$ & $0.59 \pm 0.03$ & $0.54 \pm 0.06$ & $3.01 \pm 0.39$ & $0.95 \pm 0.12$ & $1.37 \pm 0.18$ & $2.75 \pm 0.33$ \\
\hline KOM37 & $3.6 \pm 0.05$ & $11.12 \pm 1.05$ & $0.25 \pm 0.05$ & $1.06 \pm 0.14$ & $0.61 \pm 0.37$ & $0.54 \pm 0.06$ & $3.09 \pm 0.34$ & $0.87 \pm 0.09$ & $1.29 \pm 0.15$ & $2.76 \pm 0.30$ \\
\hline
\end{tabular}

Table 5.a. Calculation of $\mathrm{D}_{\text {env }}$ value based on sample Kommos 26. AGE value refers to the established archaeological age. 5.b. Calculation of average K and dose rate ( $\left(\mathrm{DR}^{\prime}\right)$ values for samples Kommos 27,37 . Where $\mathrm{D}_{\alpha}$, the effective $\alpha$ - dose rate values (for Kommos 26 , a-value $0.11 \pm 0.03$, for Kommos $27,0.09 \pm 0.02$ and

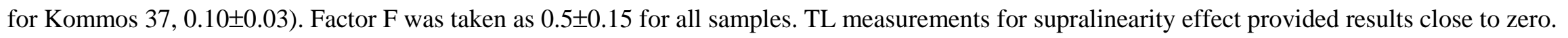




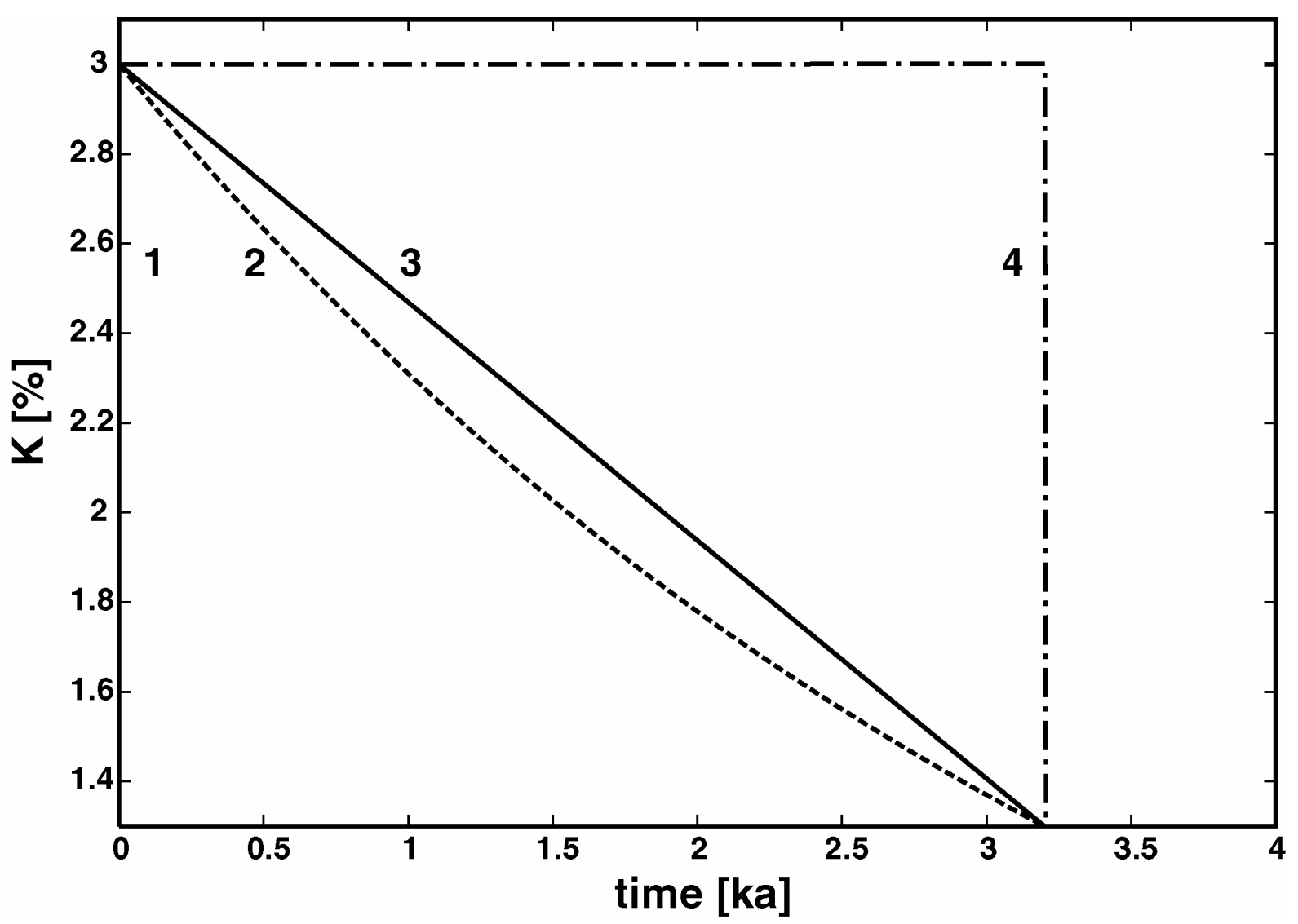

Figure 1. Schematic illustration of the four leaching models proposed for the MB and MBKR pottery groups: 1: early, 2: exponential, 3: linear, 4: late. 

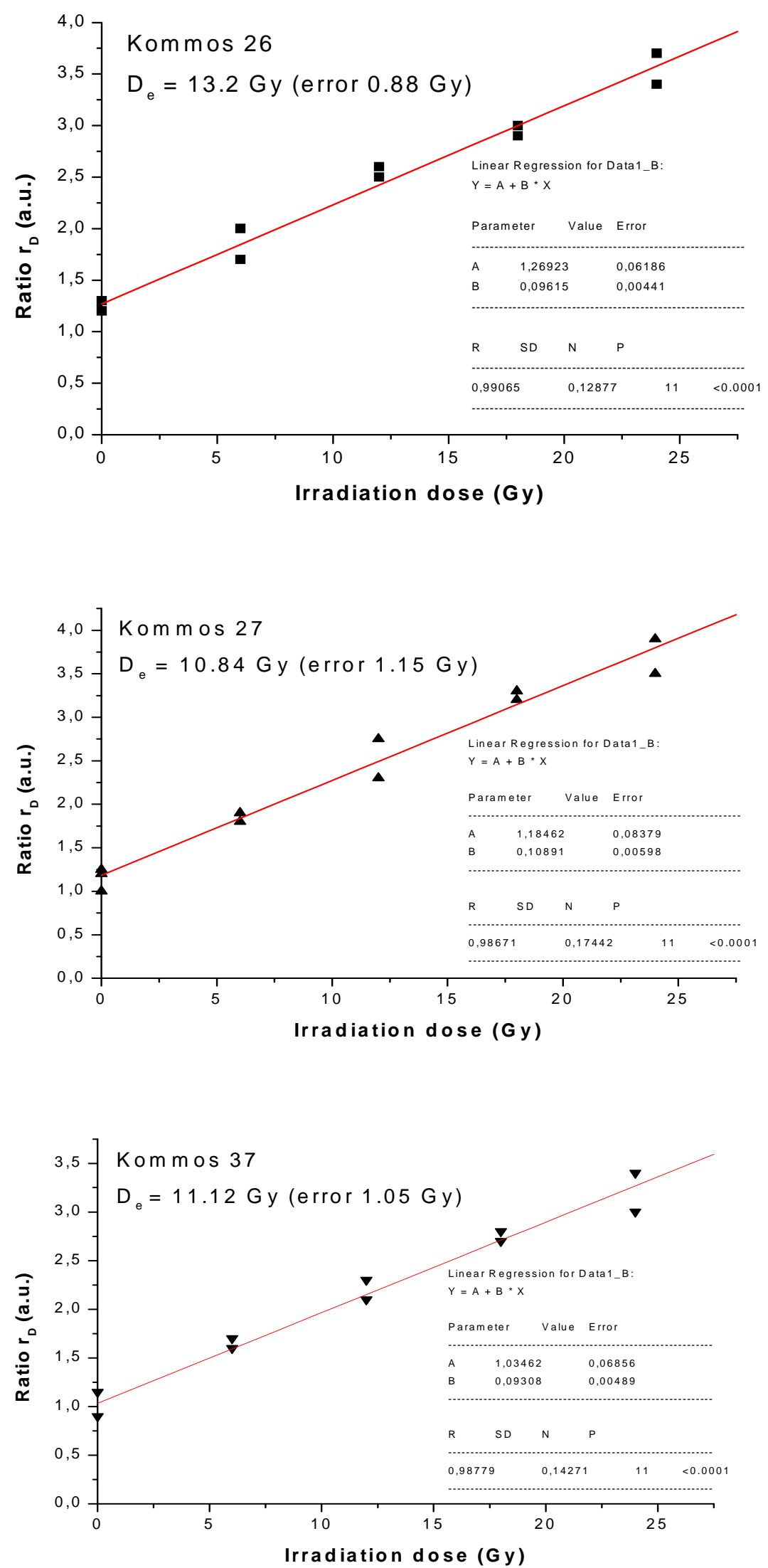

Figure 2. Normalized beta-dose growth curves for $\mathrm{D}_{\mathrm{e}}$ estimation. A laboratory irradiation dose of 10 Gy was used for inter-aliquot normalization. 